\title{
Beaver Stadium: A Decision Case in Football Field Management
}

\author{
A. J. Turgeon*
}

\begin{abstract}
Difficult decisions are not unusual for sports turf managers whose work requires them to sustain high quality levels despite tight scheduling, heavy traffic, and damaging play. During a football game against Rutgers in the fall of 1993, Bob Hudzik wondered what he would do to deal with the disaster evident on the Penn State University playing field. The sod planted 2 mo earlier was being torn and lifted with each play in the soaking rain and the field was becoming a muddy mess. The underlying problem, which required periodic resodding, was the poor internal drainage due to the presence of a gravel blanket 45 to $53 \mathrm{~cm}$ below the surface of the silt loam soil installed during the field's establishment in 1959. This case focuses on Bob's decision regarding what action to take to address the immediate problem of restoring the field to a playable condition while solving the internal drainage problem as well. Objectives of the case are for students to identify, analyze, and discuss these issues and to propose and defend a course of action for Bob Hudzik. The case has been used successfully in a senior-level capstone course in turfgrass management.
\end{abstract}

$\mathrm{P}$ EnN State University's Beaver Stadium has a reputation as one of the finest football fields in the nation. This largely reflects the competency of its field manager, Bob Hudzik, who earned his certificate in turfgrass management at Penn State. Bob developed a reputation for producing and maintaining consistently high quality turf at Beaver Stadium. Notwithstanding his long-term success, Bob knew that, given the internal drainage problems of the field dating back to its construction several decades earlier, there was a disaster waiting to happen. In the fall of 1993 during the annual football game with Rutgers, the long-awaited disaster finally occurred. This case was developed to provide students with insight into complex drainage problems and to the thought processes and perspectives of a respected athletic-field manager as he considers a particularly difficult problem.

\section{THE CASE}

During Penn State University's game with Rutgers in 1993, Bob Hudzik wondered how he would cope with the disaster occurring before his eyes. It was raining hard and the field looked like it was exploding. The sod laid 2 mo earlier was lifting and forming convoluted piles wherever there was play. Obviously, there were no roots to anchor the sod. With the saturated condition of the turf, the physical stresses of play easily cleaved the sod from the underlying soil. While football players can be expected to slip on a wet field, this field was unplayable. It was also embarrassing-despite

Department of Agronomy, 116 ASI Bldg., Pennsylvania State Univ., University Park, PA 16801-3504. Received 26 Jan. 1999. *Corresponding author(aturgeon@psu.edu).

Published in J. Nat. Resour. Life Sci. Educ. 28:74-78 (1999). http://www.JNRLSE.org having one of the world's premiere turfgrass programs, Penn State's football field was now in the worst imaginable condition. Bob wondered if he would still have a job at the end of the day. And, if so, what he would do to correct this mess.

\section{The Field Manager}

Bob Hudzik graduated from Penn State's technical program in turfgrass management in 1976. Despite having completed $2 \mathrm{yr}$ as an undergraduate agronomy major, he switched to the 36-wk technical program because he believed it would better prepare him for a professional career as a turfgrass manager. Shortly after graduation, he secured a position with Penn State's Office of Physical Plant in campus turf maintenance. The following year, his responsibilities expanded to include athletic fields. His job changed again in 1978 when he was promoted to superintendent of all university golf courses and athletic fields, a position he held for the next $13 \mathrm{yr}$. Then in 1991, Bob chose to solely manage the athletic fields and buildings, an 80-ha complex, which included Beaver Stadium.

\section{The Administration}

The administrative structure of the Athletic Department in the early 1990s included the athletic director and three associate directors: one for men's sports, a second for women's sports, and a third for sports information. The associate director for men's sports also had responsibility for all campus sports facilities and served as Bob's direct supervisor. An assistant director supported each associate director, and all of the coaches within the Athletic Department reported to one of the two assistant directors for either men's or women's sports.

The coaches oversee a wide variety of sports, most of which are played on Bob's turf. In addition to football, the athletic fields support baseball, softball, lacrosse, soccer, track and field, and a variety of club sports including rugby, cricket, and field hockey. Bob always felt that satisfying the coaches was one of his greatest challenges. His challenge was finding the resources to do what they wanted. For example, because of poor drainage, some fields didn't play well for days following a heavy rain. And because many of the fields didn't have irrigation, he was not able to sustain vigorous turfgrass growth during dry periods and provide the resiliency desired for optimum playing conditions. The demand for the resources needed to address these needs far exceeded the financial resources, and turf improvement had never been high on the priority list.

Bob's communication with the football coach was usually through intermediaries. The exception was when the coach was dissatisfied with the field at Beaver Stadium and would directly and forcefully communicate his concerns. Bob usually accepted these comments and concerns without verbal response. At the Rutgers game in the fall of 1993, the coach was not happy. Bob knew this even before the coach walked over to voice his complaints. 


\section{Field Construction and Conditions}

Personnel from Penn State's Office of Physical Plant oversaw the construction of the football field at Beaver Stadium by an outside contractor in 1959. After excavating down to the subsoil, a coarse gravel blanket $15 \mathrm{~cm}$ thick was installed containing drain tiles spaced $1.8 \mathrm{~m}$ apart (Fig. 1). A 45- to 53-cm layer of silt loam soil was placed on top of the gravel, fine graded, fertilized, and limed in preparation for sodding (Harper, 1969). Strips of 'Merion' Kentucky bluegrass (Poa pratensis L.) sod measuring 45 by $180 \mathrm{~cm}$ were planted. Additional soil was worked into the cracks separating sod strips to minimize the potential for desiccation at the edges. An irrigation program was initiated to promote rooting and sustain shoot growth. By the time the new turf was fully established, however, a serious internal drainage problem was evident (Fig. 2). The field would remain saturated for extended periods and water would stand in depressed areas along the sidelines after each rain.

In 1960 a portion of the sod was removed, additional soil was added, and the sod was replaced, to provide a $25-\mathrm{cm}$ crown down the center of the field. Catch basins were added to carry standing water along the sidelines to drain pipes located in the gravel layer. These changes were made to accelerate surface drainage and subsequent removal of

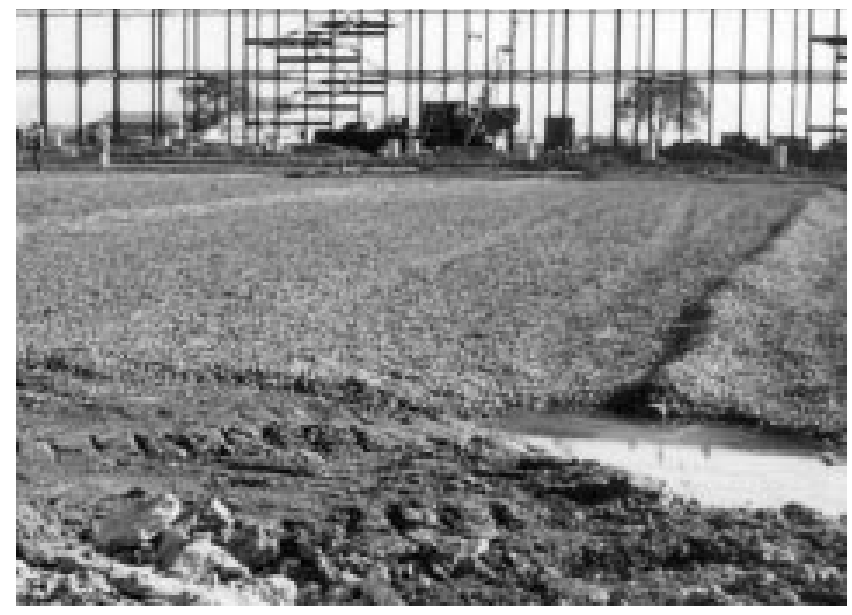

Fig. 1. Installation of gravel blanket during construction in 1959.

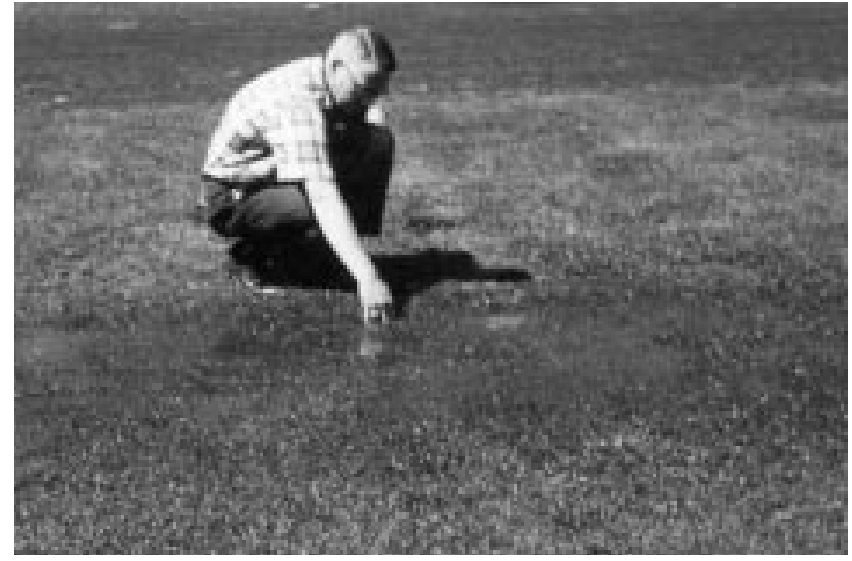

Fig. 2. Surface water along sideline, indicating poor internal drainage in 1960. standing water. While these measures did not provide an entirely satisfactory solution to the internal drainage problem, they did reduce its severity.

Another approach to deal with the drainage problem was to minimize the traffic on the field. In the late summer and fall, traffic was limited to six practice scrimmages and the six intercollegiate games that were typically scheduled at home each year. In spring, traffic was limited to the annual intersquad game and six practice scrimmages preceding it. No other events were permitted on the field. To the consternation of the director of the band, their practices were prohibited as well. When visitors arrived at the stadium, they were cautioned to restrict their activities to the sidelines and stay off the playing field. Otherwise, the only traffic allowed on the field was the array of operations associated with its maintenance.

\section{Field Maintenance}

Field maintenance included measures to carefully manage the amount of water entering the turf. This involved the installation of canvas tarps on the field whenever rainfall was expected for several days preceding a game or practice session (Fig. 3). The tarps were stored in large rolls along the sides of the field for easy access. The full- and part-time members of the maintenance crew-working at the stadium or involved in maintenance operations at any of the numerous practice and playing fields under the control of the Athletic Department-were the personnel needed to pull the tarps in place. Also, since the primary avenue by which water left the soil after infiltration was through evapotranspiration (Kneebone et al., 1992), irrigation was carefully monitored and controlled to limit the amount of water infiltrating the turf. A large travelling sprinkler with an adjustable speed control was used for irrigation. Based on the amount of moisture in the soil, the control was adjusted to set the speed at which the sprinkler traveled across the field. Given the flow rate of water through the nozzles of the sprinkler, controlling the sprinkler's rate of movement across the field controlled the amount of water applied to the turf. Through the combination of tarping and irrigation management, the turf's moisture requirements were met and a firm playing surface was maintained during the playing season.

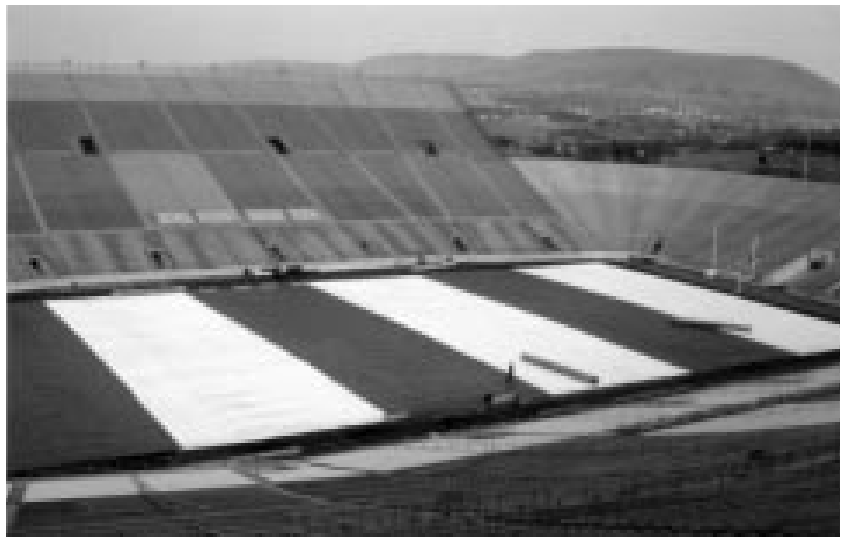

Fig. 3. Grounds-crew members installing canvas tarps on the field in anticipation of rainfall.

J. Nat. Resour. Life Sci. Educ., Vol. 28, 1999 • 75 
Mowing was also an important component of the program for maintaining proper playing conditions. Since a football turf should provide a firm and resilient surface for secure footing, but also permit fast running speeds, close mowing heights are typically employed (Turgeon, 1999). Mowing too closely, however, could reduce turfgrass recuperative capacity and lead to pest problems. At Beaver Stadium, the turf had been mowed at $24 \mathrm{~mm}$ for many years. While higher than many coaches normally preferred, Bob mowed more frequently to produce a turf of high density that looks like it is mowed lower.

A multifaceted cultivation program was employed each spring immediately following the intersquad game. This involved scalping (mowing at $16 \mathrm{~mm}$ ), vertically mowing to remove excess thatch, coring with $19-\mathrm{mm}$ diameter tines at a 5 - by $10-\mathrm{cm}$ spacing, and matting to reincorporate the cores into the turf (Turgeon, 1999). Usually, an overseeding with perennial ryegrass (Lolium perenne L.) was included just after coring but before matting.

Fertilization practices were followed to sustain healthy growth while avoiding the soft and succulent growth that often results from excessive $\mathrm{N}$ use and to maximize wear tolerance (Turgeon, 1999). This usually involved the application of a complete fertilizer in May, immediately following the cultivation program, including $73 \mathrm{~kg} \mathrm{ha}^{-1}$ from a combination of quickly available and slowly available $\mathrm{N}$ carriers. Using these same carriers, an additional $73 \mathrm{~kg}$ of $\mathrm{N}$ were applied in mid-August, followed by $10-\mathrm{kg}$ applications every 2 wk during the early part of the football season to sustain healthy growth. Finally, an additional $98 \mathrm{~kg} \mathrm{ha}^{-1}$ of slowly available $\mathrm{N}$ were applied in late October to promote fall color and root growth, and early spring green-up the next year.

In addition to cultural operations, maintenance activities also included lining the field. This involved usually two applications of an exterior latex paint before each game, and several additional applications in spring just before the intersquad game and in mid-August just before the start of the football season. At $230 \mathrm{~L}$ of paint per application and $\$ 1.35 \mathrm{~L}^{-1}$, lining the field constitutes a significant component of Bob's maintenance budget.

Regardless of the care taken to control soil water, aeration, and fertility - and protect the turf from paint-induced phytotoxicity - the turf gradually deteriorated. Annual bluegrass (Poa annua L.) and creeping bentgrass (Agrostis stolonifera L.), whose presence is often indicative of poor drainage and excessive soil compaction (Turgeon, 1999), eventually invaded. As a consequence, the field had to be resodded several times since the time it was originally established to obtain acceptable turf quality. The last resodding was in the summer of 1993.

\section{The 1993 Season}

Following the intersquad game in May 1993, all sod was cut from the field with a sod cutter and removed. The soil was deeply tilled with a chisel plow to open the compacted soil, then disked, harrowed, and graded to break up severely compacted clods. Sod that had been ordered early in the year was scheduled to arrive in early June; however, due to a severe drought lasting through the spring, the sod was not suitable for harvesting. Finally, after several false starts, replacement sod was obtained from another producer. Crews were ready to do the installation when the sod arrived 1 July. By the time the first load arrived, it was $0830 \mathrm{~h} \mathrm{(8:30}$ a.m.) and the temperature within the stadium had already exceeded $24^{\circ} \mathrm{C}$; by midday, it was $41^{\circ} \mathrm{C}$. It took a day and a half to complete the job. Large, tractor-mounted rolls of washed sod measuring $1.2 \mathrm{~m}$ across and $9.2 \mathrm{~m}$ long were unrolled and placed onto the carefully prepared planting bed. By midafternoon of the second day, all of the sod was in place and the entire field hand watered. Initially the results of the sodding operation appeared favorable. Rooting was proceeding as expected and the new turf was holding up well, despite the above-average temperatures and droughty conditions persisting through midsummer. On Friday, 13 August, just $8 \mathrm{~d}$ before the first scheduled game, however, it was obvious to nearly everyone that there was a problem. Even under light traffic, sections of sod were easily dislodged. What roots had developed earlier in the summer were now gone; the culprit was later identified by Penn State's Disease Diagnostic Lab as Magnoporthe poae, the causal organism of summer patch disease (Vargas, 1994, p. 76-79).

Bob was frantic. All of the experts consulted on possible courses of action said essentially the same thing: control desiccation while keeping the turf as dry as possible, be patient and wait for cool nighttime temperatures to stimulate new root growth, and, especially, avoid playing on the field during rainy or very wet conditions. The weather stayed dry up to and during the first two games. While numerous pieces of sod were dislodged from the soil by play, the extent of the damage was not severe and grounds-crew members repaired what they could during breaks in the games. The Rutgers game was third on the schedule. It began raining on the Thursday afternoon before game day. Tarps were placed on the field to direct all rainfall to the sidelines. The rain persisted all day Friday and into Saturday morning. Finally, just before the initiation of activities on the field at noon on Saturday, the tarps were removed. During the game, it rained constantly; sod was being pulled up by play at an accelerating rate as the game proceeded. By the end of the game, hardly a piece of sod remained where it had been before. Television and radio commentators wondered aloud why this was happening at an institution with a "world-class turfgrass program." But Bob Hudzik's communications were not limited to media people. The athletic director, the football coach, and the players all wanted to know how this could have happened and, more importantly, what he was going to do about it before the next home game.

\section{INTERPRETIVE NOTE}

\section{Case Objectives}

Upon completing the case, students should have:

1. Wrestled with the long-term feasibility of sustaining acceptable turf quality and playability under the constraints imposed by the lack of internal drainage in the field. 
2. Considered better ways to improve surface drainage to reduce the impact of poor internal drainage on the turf.

3. Explored the feasibility of developing and pursuing the goal of field reconstruction with the coaches and administrators of the Athletic Department.

4. Considered innovative approaches to addressing the internal drainage problem, given the nature of the soil and the presence of a gravel blanket 45 to $53 \mathrm{~cm}$ below the surface.

\section{Use of the Case}

This case was developed for use in a capstone course in turfgrass science, but may be suited for both formal and nonformal instruction in athletic-field turfgrass management. The case can serve to stimulate discussion of principles of soil physics, weed management, and sports turf culture. To prepare for dealing with the technical aspects of the problems presented in this case, students are encouraged to review relevant sections of a general turfgrass text (e.g., soil physics, p. 130-139; weed control, p. 234-245; and athletic fields, p. 347-351, in Turgeon, 1999). Students can also gain appreciation from the case for the social processes involved in dealing with complex problematic situations in large, bureaucratic institutions.

This case has been classroom tested several times with excellent results. Senior undergraduate turfgrass science majors in the Case Studies in Turfgrass Management course have responded well to the discussion questions. Following is an approach patterned after Bouda et al. (1996) that can be used for teaching this case:

- Students are assigned the case several days or weeks before it is to be discussed in class and are asked to review the case.

- Study questions; additional research topics; or outside readings on soil physics, weed management, and cultural operations specific to athletic fields might also be assigned to help students prepare for the in-class discussion of the case.

- The instructor may wish to begin the in-class discussion of the case by dividing the class into small groups (four to six students per group) and assigning an introductory question (such as Question 1) for discussion within the groups. This can serve to start a productive discussion by focusing on a key point in the case.

- When the small-group discussions are proceeding well and the discussion is lively, the instructor can intervene and initiate a whole-class discussion using questions such as Questions 1 through 5.

- The instructor may conclude the discussion by pressing for a consensus decision during the class. As an alternative, the instructor may suspend the discussion and ask the students to prepare a written or oral report stating their decision and the rationale for this decision. This written or oral report could also include: a detailed analysis of the situation presented in the case, an identification of the issues emerging from the analysis, a comprehensive list of decision options for addressing the issues, and an action plan for implementing the decision option selected by the individual or group.

\section{Discussion Questions and Issues in the Case}

1. Given the existence of a gravel blanket 45 to $53 \mathrm{~cm}$ below the surface, could anything be done to take advantage of this feature? This question requires students to think creatively about the possibility of turning a liability into an asset. If holes or slit trenches extending from the surface to the gravel blanket could be dug and backfilled with sand, these would significantly enhance surface drainage. Normally, openings to these channels would be threatened as fine-textured particles and turfgrass roots fill the pores near the surface; however, a sand blanket, created at the surface with the installation of sand-grown sod, could protect these openings, provide greater access to them by infiltrating water, and serve as a more favorable medium for turfgrass growth (as long as moisture and nutrient requirements were satisfied through the irrigation and fertilization programs). The increasing popularity of drill-and-fill (e.g., Floyd-McKay) systems should make most students aware of this possibility. An alternative would be to rebuild the field in accordance with USGA specifications that call for a predominantly sand medium underlain by a gravel blanket (Green Section Staff, 1993).

2. How feasible would it have been to simply plant conventional sod after the Rutgers game and continue to maintain the field as in the past? This question will challenge students to think about factors influencing the resistance of newly planted sod to cleavage from the physical stresses associated with football play. The sod would have to be sufficiently thick and heavy to remain in place under play until a substantial root system developed. And, given the poor internal drainage in this system and the likelihood of a perched water table forming above the gravel blanket, students would have to determine if the deterioration in turf quality, requiring periodic resodding in the past, would be inevitable or if it could actually be prevented through various cultural interventions.

3. Could Bob have intensified the cultivation program sufficiently to provide a better medium for sustaining healthier and more vigorous root and shoot growth? This question requires students to consider the specific effects of various turf cultivation operations. Given the availability of new hollow-tine and solid-tine (as well as drill) cultivators that can now reach well beyond the surface 8 to $10 \mathrm{~cm}$ of soil, modern cultivation methods may be more effective than earlier methods in alleviating soil compaction and its effects on turfgrass growth. However, students must recognize the limitations of these methods: they cannot improve internal drainage in a soil that has none (into the gravel blanket), and they cannot enhance evapotranspiration from the turf to an extent adequate to compensate for an internal drainage problem of this severity. Also, students must appreciate the fact that any measures directed at improving internal drainage (while allowing sufficient time for turfgrass recuperation) would be constrained by the short window of favorable growing conditions between the intersquad game in April and the initiation of summer stress in late June or early July.

4. What were Bob's options? It is important to impress on the students that the selection of a decision option may not be entirely within Bob's authority, given the resource 
limitations under which he (and most turfgrass managers) must operate and the time frames he has available to implement specific courses of action. Clearly, one option would be to rebuild the field. This might involve removing the soil and underlying gravel blanket, and modifying or replacing the existing soil with a more-suitable growth medium. An alternative might be to remove the soil but leave the gravel blanket, and install a sand medium selected to conform to USGA specifications (Green Section Staff, 1993). While these would be expensive options requiring the approval of the athletic director, they would not be suitable for restoring the field to a playable condition in time for the next game. Over the short term, the sod would have to be replaced with new sod cut sufficiently thick to remain in place despite the physical forces associated with football play. Only after the conclusion of the football season would rebuilding or major renovations be feasible.

Following resodding the field, less-expensive alternatives for improving drainage would include the drill-and-fill option (discussed under Question 1), and the intensive cultivation option (discussed under Question 3).

5. What did Bob Hudzik do to solve the problem? The instructor may choose to avoid this question because it may suggest that only one correct answer exists. An alternative would be for the instructor to share the actual decision with the students, given their curiosity about the outcome of the case.

Immediately following the Rutgers game, all of the sod was removed from the field. A supply of sand-grown sod was located and planted. Sand-grown sod was selected for its heavier weight so that it would remain in place after planting, despite the lack of a root system for anchoring it to the underlying soil. After planting, a heavy roller was used to create a smooth surface for play. Rooting was evident within $1 \mathrm{wk}$ and the sod remained in place throughout the remainder of the football season.

At the end of the football season, the maintenance crew began drilling 32-mm diameter holes into the turf extending down to the gravel blanket. The holes were backfilled with sand and all excavated soil was removed. This slow process continued throughout the 1994 season and into 1995, until a total of 102000 holes had been drilled and filled. The sand selected for filling the holes was selected to match the sand contained in the sod. This same sand was used for topdressing the field in May 1994. Immediately following the intersquad game, the field was scalped to a height of $16 \mathrm{~mm}$ and core cultivated to a depth of $89 \mathrm{~mm}$ with $25-\mathrm{mm}$ diameter hollow tines at a 5 - by $10-\mathrm{cm}$ spacing. A core harvester removed the cores as soon as they were extracted from the turf to avoid creating a fine-textured soil layer above the sand or clogging up the sand blanket with soil particles. A 13-mm thick layer of sand was then applied and matted into the turf to expand the sand blanket. While some of the sand used for topdressing filled the holes created by core cultivation, much of it expanded the sand blanket from its original thickness of approximately $50 \mathrm{~mm}$ by more than $6 \mathrm{~mm}$. This procedure has been repeated each spring since 1994.

Because the sod planted after the Rutgers game was sand grown, the silt loam soil in the field was now sandwiched between a sand blanket at the surface and a gravel blanket below. Backfilling the drill holes with sand created multiple columns connecting the sand and gravel blankets to form a unique bypass drainage system. Water infiltrating the turf first percolated through the sand blanket, accumulated at the sand-soil interface, migrated to the nearest sand column and proceeded down the column to the gravel blanket. A perched water table formed at the sand-gravel interface until a hydraulic head of sufficient volume accumulated to force the water across the interface and into the gravel where it could migrate to the drain tiles. Thus, despite the desorption resistance of the silt loam soil, the field now drained excess water for the first time.

A significant challenge was to sustain healthy turfgrass growth and quality in the relatively thin sand blanket above the silt loam soil. Changes in the fertilization program were made to compensate for the limited nutrient holding capacity of the sand. Micronutrients were added to the other fertilizer nutrients used in the program and applications of all nutrients were made at a frequency sufficient to ensure that turfgrass growth would not be seriously limited. Tarps are still used, but only during a week in which a game is scheduled and only for moderate to heavy rainfalls. Since 1994, the turf and playing quality of the field have been excellent.

\section{ACKNOWLEDGMENT}

Special appreciation is expressed to Mr. Robert Hudzik for his generous cooperation in providing information needed to develop this case.

\section{REFERENCES}

Bouda, F., J. Walker, and S. Simmons. 1996. Those "rascally" rabbits: A biological control decision case. J. Nat. Res. Life Sci. Educ. 25:137-143.

Green Section Staff. 1993. USGA recommendations for a method of putting green construction. USGA Green Section Record 3(3):1-3.

Harper, J.C. 1969. Athletic fields. p. 542-561. In A.A. Hansen and F.V. Juska (ed.) Turfgrass science. Agron. Monogr. 14. ASA, Madison, WI.

Kneebone, W.R., D.M. Kopec, and C.F. Mancino. 1992. Water requirements and irrigation. p. 441-472. In D.V. Waddington et al. (ed.) Turfgrass. Agron. Monogr. 32. ASA, CSSA, and SSSA, Madison, WI.

Turgeon, A.J. 1999. Turfgrass management. 5th ed. Prentice-Hall Publ. Co., Upper Saddle River, NJ.

Vargas, J.M. 1994. Management of turfgrass diseases. 2nd ed. Lewis Publ., Ann Arbor, MI. 